\title{
Role of the latest endovascular technology in the treatment of intermittent claudication
}

This article was published in the following Dove Press journal:

Therapeutics and Clinical Risk Management

20 June 2014

Number of times this article has been viewed

\author{
Shigeo Ichihashi \\ Kimihiko Kichikawa \\ Department of Radiology, \\ Nara Medical University, \\ Kashihara, Nara, Japan
}

Correspondence: Shigeo Ichihashi Department of Radiology, Nara Medical University, 840 Shijo-cho, Kashihara,

Nara 634-852I, Japan

$\mathrm{Tel}+81744298900$

Fax +8I7 44241988

Email shigeoichihashi@yahoo.co.jp

\begin{abstract}
Intermittent claudication is a serious symptom in patients with peripheral arterial disease, and severely limits activities of daily living. Conservative treatment (optimal medical therapy and exercise rehabilitation programs) and revascularization procedures (endovascular treatment [EVT] or open bypass surgery) can relieve intermittent claudication. Among these treatment options, EVT has developed dramatically during the past decade, and has enabled physicians to offer less invasive treatment options with increasing durability. EVT for aortoiliac lesions has matured, and its long-term patency now approaches that of open bypass surgery. The latest EVT technologies include drug-eluting stents, stent grafts, drug-coated balloons, and bioresorbable stents. The recently reported patency of stent grafts in the femoropopliteal lesions was comparable with that of the prosthetic bypass graft. In the course of the paradigm shift from bypass surgery to EVT, evidence of any long-term benefit of EVT compared with supervised exercise is still inconclusive. EVT could improve walking performance in the short-term, while supervised exercise could improve walking performance more efficiently in the long-term. Combined treatment with EVT and exercise may offer the most sustainable and effective symptom relief. This paper reviews the relevant literature on the treatment of intermittent claudication, focusing on the latest EVT technologies, and outlines a strategy for achieving long-term benefits.
\end{abstract}

Keywords: endovascular treatment, intermittent claudication, peripheral arterial disease, stent, exercise therapy

\section{Introduction}

Intermittent claudication is a common clinical manifestation of peripheral arterial disease (PAD), and affects $25 \%-33 \%$ of patients with the condition. ${ }^{1}$ Patients suffer from significant impairment in ambulatory function due to pain in the thighs, buttocks, and calves during walking, resulting in functional disability and significant lifestyle limitation. ${ }^{2,3}$ The functional limitations are associated with poorer quality of life, increased hospitalization rates, higher mortality, and higher medical costs. ${ }^{4}$ Improving functional performance with claudicants is mandatory for these patients. Optimal medical therapy, an exercise rehabilitation program, endovascular treatment (EVT), or open bypass surgery can relieve the above symptoms. ${ }^{5-7}$ Among the treatment options, EVT has an increasing role in relieving intermittent claudication in patients with PAD. ${ }^{8}$ This is due to the advent of novel EVT technologies, which enable physicians to deal with complex arterial lesions previously requiring open bypass surgery. ${ }^{9}$ EVT directly improves arterial flow and has been shown to achieve rapid regression of ischemic symptoms in a significant number of patients. ${ }^{10}$ 
However, it remains controversial whether EVT has a functional benefit for patients when compared with supervised exercise therapy. ${ }^{11}$ This paper reviews the relevant literature on the treatment of intermittent claudication, focusing on the latest EVT technologies, and outlines a strategy for achieving long-term benefits.

\section{Endovascular treatment}

Endovascular revascularization in patients with PAD has developed rapidly during the past decade. A considerable number of patients can now be offered this less invasive treatment option. According to the Inter-Society Consensus for the Management of Peripheral Arterial Disease, ${ }^{7}$ the revascularization method, ie, EVT or open surgical bypass, should be chosen based on anatomical complexity and the patient's general condition. The Inter-Society Consensus for the Management of Peripheral Arterial Disease recommends endovascular treatment for simple lesions, such as stenotic or short occlusions, and surgical bypass for complex lesions, such as diffuse, long occlusions. ${ }^{7}$ The technical success rate using EVT, even for long occlusions, now exceeds $90 \%$ due to the development of endovascular devices and increased operator expertise. In addition, EVT is less invasive and has fewer cardiovascular risks, so surgical bypass has been replaced by EVT as a primary revascularization procedure..$^{8,9,12,13}$ With regard to the culprit lesion for intermittent claudication, approximately $30 \%$ of the arterial lesions are located in the iliac arteries, and $70 \%$ are located in the femoropopliteal and tibial tract. ${ }^{14}$

\section{EVT for aortoiliac lesions}

The technical success rate using EVT for aortoiliac lesions has been reported to be $92 \%-99 \% .^{12,13,15-17}$ Even for long iliac occlusions, the technical success rate can reach $98 \% .{ }^{12} \mathrm{Com}-$ plications and 30-day mortality after EVT have been reported to be $4.8 \%-13.4 \%$ and $0 \%-0.7 \%$, respectively, which are significantly lower than the rates for bypass surgery $(18 \%$ and $2.6 \%) .{ }^{17}$ Higher primary patency could be achieved by placement of a bare metal stent (BMS), particularly for long occlusive lesions, than could be obtained using percutaneous transluminal angioplasty (PTA). ${ }^{18}$ Indes et al reported a meta-analysis comparing the clinical outcomes between EVT and surgical bypass. Primary patency rates at 5 years were superior in the open bypass group (82.7\%) compared with the EVT group (71.4\%). ${ }^{17}$ However, Soga et al reported that secondary patency, which included patency restored with reintervention, was $98.5 \%$ at 5 years, meaning that a high patency rate can be achieved with catheter-based reintervention. ${ }^{13}$

\section{EVT for femoropopliteal lesion}

The femoropopliteal artery is one of the most challenging anatomies for EVT because of its longer lesion length and smaller diameter than the iliac artery, as well as the high stress arising from the surrounding muscle contractions. ${ }^{19}$ Since the advent of the flexible, nitinol BMS, the primary patency rate for superficial femoral artery (SFA) lesions has improved. Several randomized controlled trials comparing BMS placement with PTA for 4-13 cm lesions showed a superior patency rate after BMS placement. ${ }^{20-22}$ Currently, primary nitinol stenting can be recommended as the first-line treatment for SFA lesions of intermediate length instead of PTA plus provisional stenting where stents are used only in the event of initial PTA failure (Figure 1). However, as the lesion length becomes longer, the likelihood of intimal hyperplasia increases, which results in a loss of patency. ${ }^{23,24}$ Furthermore, Scheinert et al showed that the prevalence of stent fracture became higher when longer stents or a greater number of stents were used, which could eventually cause restenosis or pseudoaneurysm formation. ${ }^{19}$

In an effort to combat neointimal hyperplasia, drug-eluting stents (DES) that enable local drug delivery to the SFA have been investigated as an alternative to BMSs. The Zilver ${ }^{\circledR}$ PTX $^{\circledR}$ (Cook Medical, Bloomington, IA, USA) is the most widely used DES incorporating paclitaxel on its outer surface. Paclitaxel inhibits microtubule assembly and selectively inhibits smooth muscle proliferation and migration, as well as extracellular matrix deposition. ${ }^{25}$ Dake et al have reported the 2-year results of their randomized trial comparing the

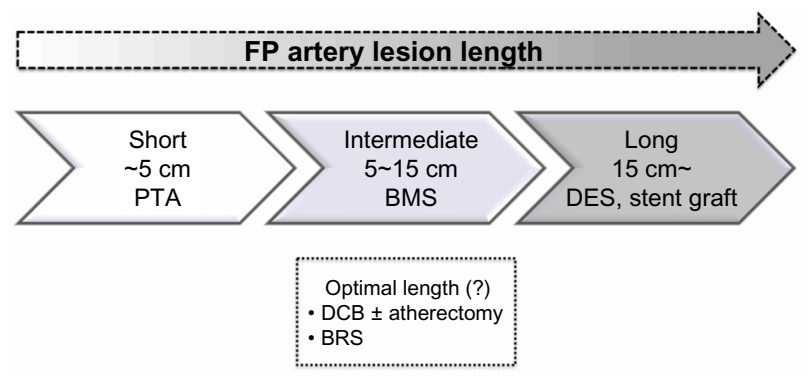

Figure I Considered stent type for each femoropopliteal lesion length. Short femoropopliteal lesions up to $5 \mathrm{~cm}$ can be treated with PTA, intermediate lesions $5-15 \mathrm{~cm}$ should be treated with BMS rather than only PTA, and a DES or stent graft can offer superior patency for longer lesions exceeding $15 \mathrm{~cm}$ compared with BMS. Other treatment strategies, such as DCB with/without atherectomy and BRS, are currently under investigation.

Abbreviations: BMS, bare metal stent; BRS, bioresorbable stent; DCB, drugcoated balloon; DES, drug eluting stent; FP, femoropopliteal; PTA, percutaneous transluminal angioplasty. 
primary patency rate for the Zilver-PTX with that of the BMS, in which patients were randomized to primary DES implantation or PTA. ${ }^{26}$ Acute PTA failure occurred in 120 patients, who underwent secondary randomization to DES or BMS placement. Compared with the PTA group, the primary DES group demonstrated a significantly superior 2 -year primary patency rate $(74.8 \%$ versus $26.5 \%)$, and in addition, the provisional DES group showed superior 2-year primary patency compared with the provisional BMS group (83.4\% versus $64.1 \%)$. Recently, Ansel presented the 4-year data for the randomized controlled Zilver-PTX trial. The 4-year primary patency rate for the paclitaxel group and the BMS group was $75 \%$ and $57.9 \%$, respectively, representing a $41 \%$ reduction in restenosis due to the paclitaxel stent coating. ${ }^{27}$ Cock et al reported that use of the Zilver-PTX could save health care costs due to the decreased need for reintervention. ${ }^{28}$

A stent graft is another option for preventing in-stent restenosis. The membrane covering a stent could prevent direct contact between blood and the diseased arterial wall, and thus could mitigate intimal hyperplasia. Two randomized studies in which the expanded polytetrafluoroethylene/nitinol stent graft (Viabahn ${ }^{\circledR}$ endoprosthesis, WL Gore and Associates, Flagstaff, AZ, USA) was compared with bypass surgery using a synthetic graft showed noninferiority of the stent graft in terms of long-term clinical outcome and primary patency rate. ${ }^{29,30}$ The VIASTAR (Gore Viabahn ${ }^{\circledR}$ endoprosthesis with bioactive Propaten ${ }^{\circledR}$ surface versus bare nitinol stent in the treatment of TASC (Trans-Atlantic Inter-Society Consensus) $\mathrm{B}, \mathrm{C}$ and $\mathrm{D}$ lesions in superficial femoral artery occlusive disease) trial, in which patients with long SFA lesions were randomized to either a Viabahn stent graft or a BMS, showed the stent graft to achieve significantly superior patency. ${ }^{31}$ A summary of the results of the randomized trials for SFA stents is shown in Table 1.

While the primary patency after EVT has improved due to introduction of the DES and stent graft, the management of in-stent restenosis is of growing concern with the increasing numbers of stents implanted. As for DES, late thrombosis due to delayed endothelialization is still considered as a potential risk. ${ }^{32}$ Stent grafts can also elicit severe inflammatory reactions ${ }^{33}$ and thrombus formation ${ }^{34}$ because of direct contact between the polymer and blood. Recurrent failure rates after repeat EVT for in-stent restenosis remain higher than for primary EVT, possibly because of the reduced acute gain and the inflammatory response of the arterial wall to foreign bodies..$^{35}$ Therefore, "nothing left behind" in the artery could be the ideal strategy considering the repeat EVT or bypass surgery in the future.

Atherectomy has been investigated as one of the nothing left behind strategies, which could enable us to debulk the atherosclerotic plaque by cutting or grinding it away. Ambler et al conducted a meta-analysis to compare the efficacy of atherectomy versus PTA. In addition to the study being insufficiently powered, there was no evidence

Table I Randomized clinical trials of stent placement in the superficial femoral artery

\begin{tabular}{|c|c|c|c|c|c|c|}
\hline Study & Sample size & Study design & $\begin{array}{l}\text { Lesion length } \\
(\mathrm{mm})\end{array}$ & $\begin{array}{l}\text { Primary } \\
\text { patency } \\
\text { (\% per year) }\end{array}$ & $\begin{array}{l}\text { Stent } \\
\text { fracture (\%) }\end{array}$ & Reference \\
\hline FAST & $\begin{array}{l}\mathrm{n}=244 \\
\text { BMS I23 } \\
\text { PTA I } 2 \text { I }\end{array}$ & $\begin{array}{l}\text { Multicenter, } \\
\text { randomized }\end{array}$ & $\begin{array}{l}\text { BMS 45.2 } \pm 27.9 \\
\text { PTA 44.5 } \pm 28\end{array}$ & $\begin{array}{l}\text { BMS 68\% } \\
\text { PTA 61\% }\end{array}$ & BMS 12 & Krankenberg et $\mathrm{al}^{69}$ \\
\hline RESILIENT & $\begin{array}{l}\mathrm{n}=206 \\
\text { BMS I53 } \\
\text { PTA 8I }\end{array}$ & $\begin{array}{l}\text { Multicenter, } \\
\text { randomized }\end{array}$ & $\begin{array}{l}\text { BMS } 70 \pm 44.3 \\
\text { PTA } 64.4 \pm 40.7\end{array}$ & $\begin{array}{l}\text { BMS } 81.5 \% \\
\text { PTA } 36.7 \%\end{array}$ & BMS 3.I\% & Laird et $\mathrm{al}^{22}$ \\
\hline ASTRON & $\begin{array}{l}\mathrm{n}=73 \\
\text { BMS } 34 \\
\text { PTA } 39\end{array}$ & $\begin{array}{l}\text { Multicenter, } \\
\text { randomized }\end{array}$ & $\begin{array}{l}\text { BMS } 82 \pm 67 \\
\text { PTA } 65 \pm 46\end{array}$ & $\begin{array}{l}\text { BMS } 54 \% \\
\text { PTA } 31 \%\end{array}$ & NA & Dick $P$ et $\mathrm{al}^{70}$ \\
\hline $\begin{array}{l}\text { ABSOLUTE } \\
\text { VIENNA }\end{array}$ & $\begin{array}{l}\mathrm{n}=104 \\
\text { BMS } 51 \\
\text { PTA } 53\end{array}$ & $\begin{array}{l}\text { Single-center } \\
\text { randomized }\end{array}$ & $\begin{array}{l}\text { BMS } 101 \pm 75 \\
\text { PTA } 92 \pm 64\end{array}$ & $\begin{array}{l}\text { BMS 63.3\% } \\
\text { PTA } 36.5 \%\end{array}$ & BMS I.5\% & Schillinger et $\mathrm{al}^{20}$ \\
\hline $\begin{array}{l}\text { Zilver }^{\circledR}-\mathrm{PT} \mathrm{X}^{\circledR} \\
\text { randomized } \\
\text { clinical study }\end{array}$ & $\begin{array}{l}\mathrm{n}=479 \\
\text { DES 24I } \\
\text { PTA } 238\end{array}$ & $\begin{array}{l}\text { Multicenter, } \\
\text { randomized }\end{array}$ & $\begin{array}{l}\text { DES } 66.4 \pm 38.9 \\
\text { PTA } 63.1 \pm 40.7\end{array}$ & $\begin{array}{l}\text { DES } 83.1 \% \\
\text { PTA } 32.8 \%\end{array}$ & DES $0.9 \%$ & Dake et $\mathrm{al}^{66}$ \\
\hline $\begin{array}{l}\text { VIASTAR } \\
\text { clinical trial }\end{array}$ & $\begin{array}{l}\mathrm{n}=|4| \\
\text { Stent graft } 72 \\
\text { BMS } 69\end{array}$ & $\begin{array}{l}\text { Multicenter, } \\
\text { randomized }\end{array}$ & $\begin{array}{l}\text { Stent graft } 190 \pm 63 \\
\text { BMS I } 73 \pm 66\end{array}$ & $\begin{array}{l}\text { Stent graft } 78 \% \\
\text { BMS } 54 \%\end{array}$ & NA & Lammer et $\mathrm{al}^{31}$ \\
\hline
\end{tabular}

Note: Zilver ${ }^{\circledR}-\mathrm{PTX}^{\circledR}$; Cook Medical, Bloomington, IA, USA.

Abbreviations: BMS, bare metal stent; DES, drug-eluting stent; NA, not available; PTA, percutaneous transluminal angioplasty. 
to support the superiority of atherectomy over PTA in terms of patency or target lesion revascularization. ${ }^{36}$

Drug-coated balloons (DCB) have also been investigated as one of the nothing left behind strategies, offering a mechanism by which to deliver antiproliferative drugs directly to the diseased arterial wall without a stent scaffold. The majority of the DCB trials have used paclitaxel, which is highly lipophilic, allowing rapid intracellular uptake. Randomized controlled trials, such as THUNDER (ClinicalTrials.gov identifier NCT00156624), ${ }^{37}$ FemPac (Femoral-Paclitaxel), ${ }^{38}$ and LEVANT I (ClinicalTrials.gov identifier NCT00930813), ${ }^{39}$ have shown significant reductions in late lumen loss and reintervention after treatment by DCB compared with conventional balloon angioplasty. However, severe calcification of the atherosclerotic lesion is responsible for a poor response to balloon dilation, due to significant acute vessel recoil and frequent flow-limiting dissections. Calcified plaque could also inhibit drug penetration into the arterial wall. Atherectomy has been combined with DCB in an attempt to reduce the plaque burden and achieve sufficient drug penetration. Cioppa et al investigated the combination of atherectomy and DCB for heavily calcified SFA lesions in 30 patients. ${ }^{40}$ The minimal lumen diameter measured by intravascular ultrasound was $1.2 \pm 0.9 \mathrm{~mm}$ before procedure and $5.1 \pm 0.8 \mathrm{~mm}$ after atherectomy and DCB. The target lesion revascularization rate at 1 year was $10 \%$. A combined strategy of atherectomy and DCB could offer sufficient acute gain of lesions, as well as suppression of intimal hyperplasia. Preliminary findings were recently presented for DEFINITIVE AR (Directional AthErectomy Followed by a PaclItaxel-Coated BallooN to InhibiT RestenosIs and Maintain Vessel PatEncy: A Pilot Study of Anti-Restenosis Treatment), in which patients were randomly allocated to treatment with a drug-coated balloon alone $(n=54)$ or atherectomy followed by DCB $(n=48)$. The technical success rate, defined as $\leq 30 \%$ residual stenosis of the target lesion, for atherectomy and DCB was significantly higher than that for DCB alone, and the flow-limiting dissection rate was significantly lower with atherectomy and DCB. ${ }^{41}$ DCB has been demonstrated to offer superior patency when compared with a conventional balloon in femoropopliteal lesions; however, it should be noted that the published reports to date lack long-term data regarding the efficacy of DCB. Further, the recently presented INPACT-DEEP trial (ClinicalTrials.gov identifier NCT00941733) showed that DCB had no benefits in terms of avoiding target lesion revascularization and a higher prevalence of severe complications, such as major amputations, than a conventional balloon when DCB was used in patients suffering from critical limb ischemia due to a below-knee lesion. ${ }^{42}$

Bioresorbable stents could be another possibility. These are designed to provide a temporary architectural scaffold for the arterial wall to avoid vessel recoil, eventually disappearing by bioabsorption. Disappearance of the rigid scaffold can facilitate recovery of vasomotion, adaptive shear stress, late luminal enlargement, and expansive remodeling. Once bioabsorption of the temporary scaffold has been completed, the potential risk of stent thrombosis could be reduced and there may be no requirement for long-term dual antiplatelet therapy. ${ }^{43}$ Further, the nonmetallic scaffold does not restrict the use of noninvasive imaging such as computed tomography or magnetic resonance imaging. The most frequently used biodegradable polymer is poly-L-lactic acid, which is metabolized into lactic acid, carbon dioxide, and water. ${ }^{44}$

The Igaki-Tamai stent (Kyoto Medical Planning Company, Kyoto, Japan) is the first bioresorbable stent to be implanted in human coronary arteries, with complete degradation taking 18-24 months. The first-in-human clinical study of the Igaki-Tamai stent involving 15 patients with 19 lesions demonstrated no major adverse cardiovascular events or stent thrombosis within 30 days, with one repeat percutaneous coronary intervention at the 6-month follow-up. ${ }^{45}$ At 10 -year clinical follow-up, freedom from cardiac death, noncardiac death, and major adverse cardiovascular events was $98 \%$, $87 \%$, and $48 \%$, respectively. ${ }^{46}$ Igaki-Tamai stents were also implanted in SFA lesions and evaluated in the PERSEUS study (ClinicalTrials.gov identifier NCT00484315), which recruited 45 patients with de novo SFA lesions. ${ }^{47}$ The initial technical success rate was reported to be $100 \%$, with no serious adverse events. The 6-month angiographic results revealed no reocclusions, although symptomatic restenosis occurred in $20 \%$ of patients. Use of bioresorbable stents in the SFA was demonstrated to be feasible and the results were very encouraging. Currently, the safety of the drug-eluting bioresorbable vascular scaffold is being evaluated in the ESPRIT I trial (ClinicalTrials.gov identifier NCT01468974), and restenosis has not been reported within the past 6 months. ${ }^{48}$

\section{Which is more effective for symptom relief: EVT for iliac or femoropopliteal lesions?}

Patients with aortoiliac lesions are often more symptomatic than those with femoropopliteal lesions because those with aortoiliac lesions have more ischemic muscle mass with 
walking, and there may be no substantial collateral arteries. Thus, patients with aortoiliac lesions could have effective symptom relief after EVT. In the MIMIC (Mild to Moderate Intermittent Claudication) trial, 34 patients with occlusive aortoiliac disease and 93 patients with femoropopliteal disease were randomized to combined therapy of supervised exercise plus EVT or to supervised exercise only. ${ }^{49}$ Compared with the supervised exercise group, the adjusted absolute walking distance was $38 \%$ greater in the supervised exercise plus EVT group for the femoropopliteal trial, and $78 \%$ greater in the supervised exercise plus EVT group for the aortoiliac trial. Although low recruitment and eligibility rates and high dropout rates could limit the impact of the results, this study was able to demonstrate the benefit of adjunctive EVT, particularly for aortoiliac lesions.

Chetter et al also demonstrated superior relief of claudication with iliac angioplasty when compared with SFA angioplasty. ${ }^{49}$ Quality of life, particularly physical functioning, in patients with iliac lesions approached that in an age-matched population after EVT. Ichihashi et al evaluated improvement in intermittent claudication when only occlusive iliac artery disease was treated by EVT in patients having concomitant iliac and SFA lesions. ${ }^{51}$ Despite the remaining SFA lesions, $87 \%$ of patients had symptomatic relief, translating into at least one category upgrade in the Rutherford classification after stent placement for iliac artery lesions. Further, $72 \%$ of patients were completely relieved of intermittent claudication. The indications for treatment of SFA lesions could be evaluated when symptom relief is not enough to improve patient quality of life after treatment of iliac lesions.

\section{Relief of symptoms of intermittent claudication after EVT versus exercise therapy}

In patients with PAD, exercise therapy is also effective in improving symptoms and increasing walking capacity. Supervised exercise increases maximal treadmill walking distance by $50 \%-200 \%$ in patients with PAD. ${ }^{6,52}$ Several trials have compared exercise therapy and EVT with regard to their ability to improve intermittent claudication. Spronk et al compared the cost-effectiveness of EVT with that of supervised exercise in patients with intermittent claudication. No significant difference was found between the two therapies, but the costs of EVT were significantly higher than for exercise therapy. ${ }^{53}$ The recent CLEVER trial (ClinicalTrials.gov identifier NCT00132743) randomized 111 patients with occlusive aortoiliac disease to receive optimal medical care, optimal medical care plus supervised exercise, or optimal medical care plus EVT. ${ }^{54}$ Supervised exercise resulted in superior treadmill walking performance compared with EVT; however, the greatest improvement in self-reported quality of life was observed in the EVT cohort. A systematic review of eight randomized controlled trials comparing supervised or unsupervised exercise therapies with EVT failed to demonstrate the superiority of any particular therapy with regard to walking distance and quality of life. ${ }^{55}$ Another systematic review by Liu et al indicated that the independent effect of EVT could improve walking performance in the short-term, but not in the long-term, while supervised exercise could improve walking performance more efficiently in the long term. ${ }^{56}$ Mazari et al reported the results of a randomized controlled trial comparing the effectiveness of EVT versus supervised exercise for symptomatic relief in patients with femoropopliteal lesions. EVT and supervised exercise showed equal effectiveness in symptom relief, and in addition, a combination of EVT and supervised exercise achieved more sustained clinical improvement. ${ }^{57}$ However, supervised exercise is typically not covered by medical insurance, and involves regular transport to an exercise center. Thus, few patients with PAD can participate in consistent supervised treadmill exercise therapy. ${ }^{58}$

Home-based walking exercise is a promising alternative to supervised exercise. GOALS (Group Oriented Arterial Leg Study) is a randomized controlled trial that investigated whether a home-based exercise regimen can improve functional performance in patients with PAD when compared with a health education control group. ${ }^{59}$ Participants met once weekly for 90 minutes with other PAD participants for the entire 6 months of the intervention, and all participants were instructed in the benefits of walking exercise, how to exercise, and self-monitoring. After 6 months, the home-based walking exercise program significantly improved walking distance and speed in patients with PAD. Therefore, homebased walking programs should be recommended for patients with PAD who are not eligible for supervised exercise, when a weekly group-mediated cognitive behavioral intervention is conducted. Mays et al also reported in their review literature that community walking programs with regular feedback and monitoring result in improvements in walking performance. ${ }^{60}$ The effectiveness of a combination of exercise and EVT was evaluated in the MIMIC trial, ${ }^{49}$ the purpose of which was to investigate whether there was an adjuvant benefit from EVT over supervised exercise with optimal medical therapy in the treatment of intermittent claudication. EVT was demonstrated to confer adjuvant benefit over supervised exercise 
with optimal medical therapy in terms of walking distance. Further, Mazari et $\mathrm{al}^{57}$ reported that a combination of EVT and supervised exercise achieved more sustained clinical improvement than EVT or exercise alone.

\section{Medical treatment as an adjunctive therapy for EVT}

Only two medications, ie, pentoxifylline and cilostazol, are currently approved by the US Food and Drug Administration for the treatment of PAD-associated walking impairment. However, a recent systematic review concluded that pentoxifylline and cilostazol are associated with an improvement in maximal treadmill walking distance of only $15 \%$ and $25 \%$, respectively. ${ }^{61}$ In a meta-analysis of nine trials comparing cilostazol with placebo, cilostazol was associated with an absolute improvement in walking distance of $42.1 \mathrm{~m}$ compared with placebo. ${ }^{62}$ Ramipril, one of the angiotensin-converting enzyme inhibitors, was demonstrated to be effective in improving walking performance in a randomized controlled trial. ${ }^{63}$ However, a recent meta-analysis by Shahin et al, including four randomized trials, demonstrated no association between use of angiotensin-converting enzyme inhibitors and improved walking performance. ${ }^{64}$ Medical therapy alone could be insufficient to improve symptoms, so adjunctive EVT with/ without exercise therapy is required. Momsen et al conducted a meta-analysis evaluating the efficacy of medical therapies in improving walking capacity. Lipid-lowering drugs seem to be the most efficient therapy, increasing maximal walking distance to $160 \mathrm{~m} .^{5}$

Antiplatelet therapy has an important role in reducing thrombosis or restenosis after EVT. Most physicians favor indefinite aspirin therapy and a minimum 4-week course of a second thienopyridine anti-platelet agent after stent placement. ${ }^{65}$ More recent experience with the paclitaxeleluting stent suggests that 2 months of dual antiplatelet therapy followed by indefinite aspirin is associated with low rates of acute stent thrombosis. ${ }^{66}$ Strobl et al conducted the randomized, single-center MIRROR study (ClinicalTrials. gov identifier NCT00163267) which randomized 80 patients to either aspirin plus clopidogrel or aspirin plus placebo for preinterventional and post-interventional therapy. ${ }^{67}$ Only BMSs were used for stent placement. At 6 months, patients receiving clopidogrel had significantly lower rates of target lesion revascularization compared with placebo (5\% versus $20 \%$ ). However, after cessation of the clopidogrel/placebo at 6 months, there was no significant difference in target lesion revascularization at 12 months after treatment (25\% versus
$32.4 \%$ ). Patients who are also at high risk for restenosis, such as those with long, heavily calcified lesions, would be potential candidates for prolonged or even indefinite dual antiplatelet therapy.

Cilostazol has been demonstrated to have the potential to reduce in-stent restenosis. STOP-IC (ClinicalTrials. gov identifier NCT00163267), a prospective, multicenter, randomized controlled trial involving 200 patients treated with femoropopliteal stents, showed that treatment with cilostazol significantly reduced the rate of in-stent restenosis when compared with placebo $(20 \%$ versus $49 \%$, respectively) ${ }^{68}$ The duration and intensity of antiplatelet therapy must be balanced against the bleeding risk in each patient.

\section{Conclusion}

Advances in EVT have prompted many physicians to consider more liberal indications of EVT for intermittent claudication with PAD. EVT can achieve effective symptom relief and a patency rate almost comparable with that of bypass surgery in patients with aortoiliac lesions. For femoropopliteal lesions, there is still room for improvement with EVT because patency decreases with increasing length, poor runoff, and diabetes. The use of new technology such as the DES, DCB, stent graft, and bioabsorbable stent seems promising; however, more liberal use of EVT for femoropopliteal lesions should be delayed until its efficacy and durability for treatment of intermittent claudication is demonstrated by large-scale studies. To date, multiple randomized controlled trials have shown no significant difference in effectiveness with regard to symptom relief between EVT and exercise therapy. EVT should be combined with exercise therapy and optimal medical therapies, including cilostazol and statins, which could offer the most effective and sustainable symptom relief for patients.

\section{Acknowledgment}

The authors appreciate the excellent advice of Marian Pahud (Valkenburg, the Netherlands) in submitting this paper.

\section{Disclosure}

The authors report no conflicts of interest in this work.

\section{References}

1. Rose GA, Blackburn H. Cardiovascular survey methods. Monogr Ser World Health Organ. 1968;56:1-188.

2. Regensteiner JG, Hiatt WR, Coll JR, et al. The impact of peripheral arterial disease on health-related quality of life in the Peripheral Arterial Disease Awareness, Risk, and Treatment: New Resources for Survival (PARTNERS) Program. Vasc Med. 2008;13:15-24.

3. McDermott MM, Liu K, Greenland P, et al. Functional decline in peripheral arterial disease: associations with the ankle brachial index and leg symptoms. JAMA. 2004;292:453-461. 
4. McDermott MM. Medications for improving walking performance in peripheral artery disease: still miles to go. JAMA. 2013;309:487-488.

5. Momsen AH, Jensen MB, Norager CB, et al. Drug therapy for improving walking distance in intermittent claudication: a systematic review and meta-analysis of robust randomized controlled studies. Eur J Vasc Endovasc Surg. 2009;38:463-474.

6. McDermott MM, Ades P, Guralnik JM, et al. Treadmill exercise and resistance training in patients with peripheral arterial disease with and without intermittent claudication: a randomized controlled trial. JAMA 2009;301:165-174.

7. Norgren L, Hiatt WR, Dormandy JA, et al; TASC II Working Group. Inter-society consensus for the management of peripheral arterial disease (TASC II). J Vasc Surg. 2007;45:S5-S67.

8. Rowe VL, Lee W, Weaver FA, Etzioni D. Patterns of treatment for peripheral arterial disease in the United States: 1996-2005. JVasc Surg. 2009;49:910-917.

9. Schillinger M, Minar E. Percutaneous treatment of peripheral artery disease: novel techniques. Circulation. 2012;126:2433-2440.

10. O'Brien-Irr MS, Harris LM, Dosluoglu HH, Dryjski ML. Endovascular intervention for treatment of claudication: is it cost-effective? Ann Vasc Surg. 2010;24:833-840.

11. Ahimastos AA, Pappas EP, Buttner PG, Walker PJ, Kingwell BA, Golledge J. A meta-analysis of the outcome of endovascular and noninvasive therapies in the treatment of intermittent claudication. J Vasc Surg. 2011;54:1511-1521.

12. Ichihashi S, Higashiura W, Itoh H, Sakaguchi S, Nishimine K, Kichikawa K. Long-term outcomes for systematic primary stent placement in complex iliac artery occlusive disease classified according to Trans-Atlantic Inter-Society Consensus (TASC)-II. J Vasc Surg. 2011;53:992-999.

13. Soga $\mathrm{Y}$, Iida $\mathrm{O}$, Kawasaki D, et al. Contemporary outcomes after endovascular treatment for aorto-iliac artery disease. Circ J. 2012;76: 2697-2704.

14. Balzer JO, Thalhammer A, Khan V, Zangos S, Vogl TJ, Lehnert T. Angioplasty of the pelvic and femoral arteries in PAOD: results and review of the literature. Eur J Radiol. 2010;75:48-56.

15. Sixt S, Krankenberg H, Möhrle C, et al. Endovascular treatment for extensive aortoiliac artery reconstruction: a single-center experience based on 1712 interventions. J Endovasc Ther. 2013;20:64-73.

16. Ozkan U, Oguzkurt L, Tercan F. Technique, complication, and long-term outcome for endovascular treatment of iliac artery occlusion. Cardiovasc Intervent Radiol. 2010;33:18-24.

17. Indes JE, Pfaff MJ, Farrokhyar F, et al. Clinical outcomes of 5358 patients undergoing direct open bypass or endovascular treatment for aortoiliac occlusive disease: a systematic review and meta-analysis. $J$ Endovasc Ther. 2013;20:443-455.

18. AbuRahma AF, Hayes JD, Flaherty SK, Peery W. Primary iliac stenting versus transluminal angioplasty with selective stenting. J Vasc Surg. 2007;46:965-970.

19. Scheinert D, Scheinert S, Sax J, et al. Prevalence and clinical impact of stent fractures after femoropopliteal stenting. $\mathrm{J} \mathrm{Am} \mathrm{Coll} \mathrm{Cardiol.}$ 2005;45:312-315.

20. Schillinger M, Sabeti S, Loewe C, et al. Balloon angioplasty versus implantation of nitinol stents in the superficial femoral artery. $N$ Engl J Med. 2006;354:1879-1888.

21. Bosiers M, Torsello G, Gissler HM, et al. Nitinol stent implantation in long superficial femoral artery lesions: 12-month results of the DURABILITY I study. $J$ Endovasc Ther. 2009;16:261-269.

22. Laird JR, Katzen BT, Scheinert D, et al. Nitinol stent implantation versus balloon angioplasty for lesions in the superficial femoral artery and proximal popliteal artery: twelve-month results from the RESILIENT randomized trial. Circ Cardiovasc Interv. 2010;3: 267-276.

23. Soga Y, Iida O, Hirano K, Yokoi H, Nanto S, Nobuyoshi M. Mid-term clinical outcome and predictors of vessel patency after femoropopliteal stenting with self-expandable nitinol stent. $J$ Vasc Surg. 2010;52:608-615.
24. Dohi T, Iida O, Soga Y, et al. Incidence, predictors, and prognosis of in-stent occlusion after endovascular treatment with nitinol stents for femoropopliteal lesions. J Vasc Surg. 2014;59:1009-1015. e1.

25. Axel DI, Kunert W, Goggelmann C, et al. Paclitaxel inhibits arterial smooth muscle cell proliferation and migration in vitro and in vivo using local drug delivery. Circulation. 1997;96:636-645.

26. Dake MD, Ansel GM, Jaff MR, et al. Sustained safety and effectiveness of paclitaxel-eluting stents for femoropopliteal lesions: 2-year follow-up from the Zilver PTX randomized and single-arm clinical studies. J Am Coll Cardiol. 2013;61:2417-2427.

27. Ansel G. Zilver PTX randomized trial of paclitaxel-eluting stents for femoropopliteal artery disease: 4 year results. Abstract presented at the 2013 Vascular Interventional Advances meeting, Las Vegas, NV, USA, October 8-11, 2013.

28. De Cock E, Sapoval M, Julia P, de Lissovoy G, Lopes S. A budget impact model for paclitaxel-eluting stent in femoropopliteal disease in France. Cardiovasc Intervent Radiol. 2013;36:362-370.

29. Kedora J, Hohmann S, Garrett W, Munschaur C, Theune B, Gable D. Randomized comparison of percutaneous Viabahn stent grafts vs prosthetic femoral-popliteal bypass in the treatment of superficial femoral arterial occlusive disease. J Vasc Surg. 2007;45:10-16.

30. McQuade K, Gable D, Pearl G, Theune B, Black S. Four-year randomized prospective comparison of percutaneous ePTFE/nitinol self-expanding stent graft versus prosthetic femoral-popliteal bypass in the treatment of superficial femoral artery occlusive disease. $J$ Vasc Surg. 2010;52:584-590.

31. Lammer J, Zeller T, Hausegger KA, et al. Heparin-bonded covered stents versus bare-metal stents for complex femoropopliteal artery lesions: the randomized VIASTAR trial (Viabahn endoprosthesis with PROPATEN bioactive surface [VIA] versus bare nitinol stent in the treatment of long lesions in superficial femoral artery occlusive disease). J Am Coll Cardiol. 2013;62:1320-1327.

32. Joner M, Finn AV, Farb A, et al. Pathology of drug eluting stents in humans: delayed healing and late thrombotic risk. J Am Coll Cardiol. 2006;48:193-202.

33. Farhatnia Y, Tan A, Motiwala A, Cousins BG, Seifalian AM. Evolution of covered stents in the contemporary era: clinical application, materials and manufacturing strategies using nanotechnology. Biotechnol Adv. 2013;31:524-542.

34. Saxon RR, Chervu A, Jones PA, et al. Heparin-bonded, expanded polytetrafluoroethylene-lined stent graft in the treatment of femoropopliteal artery disease: 1-year results of the VIPER (Viabahn Endoprosthesis with Heparin Bioactive Surface in the Treatment of Superficial Femoral Artery Obstructive Disease) trial. J Vasc Interv Radiol. 2013;24:165-173.

35. Ryer EJ, Trocciola SM, DeRubertis B, et al. Analysis of outcomes following failed endovascular treatment of chronic limb ischemia. Ann Vasc Surg. 2006;20:440-446.

36. Ambler GK, Radwan R, Hayes PD, Twine CP. Atherectomy for peripheral arterial disease. Cochrane Database Syst Rev. 2014;3: CD006680.

37. Tepe G, Zeller T, Albrecht T, et al. Local delivery of paclitaxel to inhibit restenosis during angioplasty of the leg. $N$ Engl $J$ Med. 2008;358:689-699.

38. Werk M, Langner S, Reinkensmeier B, et al. Inhibition of restenosis in femoropopliteal arteries: paclitaxel-coated versus uncoated balloon: femoral paclitaxel randomized pilot trial. Circulation. 2008;118: $1358-1365$.

39. Scheinert D, Duda S, Zeller T, et al. The LEVANT I (lutonix paclitaxelcoated balloon for the prevention of femoropopliteal restenosis) trial for femoropopliteal revascularization: first-in-human randomized trial of low-dose drug-coated balloon versus uncoated balloon angioplasty. JACC Cardiovasc Interv. 2014;7:10-19.

40. Cioppa A, Stabile E, Popusoi G, et al. Combined treatment of heavy calcified femoro-popliteal lesions using directional atherectomy and a paclitaxel coated balloon: one-year single centre clinical results. Cardiovasc Revasc Med. 2012;13:219-223. 
41. Zeller T. Directional atherectomy followed by a Paclitaxel-coated balloon to inhibit restenosis and maintain vessel patency: a pilot study of anti-restenosis treatment. Abstract presented at the 2013 Vascular Interventional Advances meeting, Las Vegas, NV, USA, October 8-11, 2013.

42. Zeller T. DEB vs PTA for infrapopliteal revascularisation: 12 months results from the IN.PACT DEEP randomized trial. Abstract presented at the Leipzig Interventional Course, Leipzig, Germany, January 27-31, 2013.

43. Onuma Y, Serruys PW. Bioresorbable scaffold: the advent of a new era in percutaneous coronary and peripheral revascularization? Circulation. 2011;123:779-797.

44. Nair LS, Laurencin CT. Biodegradable polymers as biomaterials. Prog Polym Sci. 2007;32:762-798.

45. Tamai H, Igaki K, Kyo E, et al. Initial and 6-month results of biodegradable poly-1-lactic acid coronary stents in humans. Circulation. 2000;102:399-404.

46. Nishio S, Kosuga K, Igaki K, et al. Long-term ( $>10$ years) clinical outcomes of first-in-human biodegradable poly-L-lactic acid coronary stents: Igaki-Tamai stents. Circulation. 2012;125:2343-2353.

47. Biamino G, Schmidt A, Scheinert D. Treatment of SFA lesions with PLLA biodegradable stents: results of the PERSEUS study. J Endovasc Ther. 2005; 12:5

48. Lammer J. Evaluation of Esprit BVS in the treatment of patients with occlusive vascular disease of the superficial femoral artery (SFA) or common or external iliac arteries. Abstract presented at the 2013 Vascular Interventional Advances meeting, Las Vegas, NV, USA, October 8-11, 2013.

49. Chetter IC, Spark JI, Kent PJ, Berridge DC, Scott DJ, Kester RC. Percutaneous transluminal angioplasty for intermittent claudication: evidence on which to base the medicine. Eur J Vasc Endovasc Surg. 1998; 16:477-484.

50. Greenhalgh RM, Belch JJ, Brown LC, et al. The adjuvant benefit of angioplasty in patients with mild to moderate intermittent claudication (MIMIC) managed by supervised exercise, smoking cessation advice and best medical therapy: results from two randomised trials for stenotic femoropopliteal and aortoiliac arterial disease. Eur J Vasc Endovasc Surg. 2008;36:680-688.

51. Ichihashi S, Higashiura W, Itoh H, Sakaguchi S, Kichikawa K. Iliac artery stent placement relieves claudication in patients with iliac and superficial femoral artery lesions. Cardiovasc Intervent Radiol. 2013;36:623-628.

52. Fakhry F, van de Luijtgaarden KM, Bax L, et al. Supervised walking therapy in patients with intermittent claudication. JVasc Surg. 2012;56:1132-1142.

53. Spronk S, Bosch JL, den Hoed PT, et al. Cost-effectiveness of endovascular revascularization compared to supervised hospital-based exercise training in patients with intermittent claudication: a randomized controlled trial. J Vasc Surg. 2008;48:1472-1480.

54. Murphy TP, Cutlip DE, Regensteiner JG, et al. Supervised exercise versus primary stenting for claudication resulting from aortoiliac peripheral artery disease: six-month outcomes from the claudication: exercise versus endoluminal revascularization (CLEVER) study. Circulation. 2012;125:130-139.

55. Frans FA, Bipat S, Reekers JA, Legemate DA, Koelemay MJ. Systematic review of exercise training or percutaneous transluminal angioplasty for intermittent claudication. Br J Surg. 2012;99:16-28.
56. Liu J, Wu Y, Li Z, Li W, Wang S. Endovascular treatment for intermittent claudication in patients with peripheral arterial disease: a systematic review. Ann Vasc Surg. 2014;28:977-982.

57. Mazari FA, Khan JA, Carradice D, et al. Randomized clinical trial of percutaneous transluminal angioplasty, supervised exercise and combined treatment for intermittent claudication due to femoropopliteal arterial disease. Br J Surg. 2012;99:39-48.

58. Regensteiner JG. Exercise rehabilitation for the patient with intermittent claudication: a highly effective yet underutilized treatment. Curr Drug Targets Cardiovasc Haematol Disord. 2004;4:233-239.

59. McDermott MM, Liu K, Guralnik JM, et al. Home-based walking exercise intervention in peripheral artery disease: a randomized clinical trial. JAMA. 2013;310:57-65.

60. Mays RJ, Rogers RK, Hiatt WR, Regensteiner JG. Community walking programs for treatment of peripheral artery disease. J Vasc Surg. 2013;58:1678-1687.

61. Stevens JW, Simpson E, Harnan S, et al. Systematic review of the efficacy of cilostazol, naftidrofuryl oxalate and pentoxifylline for the treatment of intermittent claudication. Br J Surg. 2012;99:1630-1638.

62. Pande RL, Hiatt WR, Zhang P, Hittel N, Creager MA, McDermott M. A pooled analysis of the durability and predictors of treatment response of cilostazol in patients with intermittent claudication. Vasc Med. 2010;15:181-188.

63. Ahimastos AA, Walker PJ, Askew C, et al. Effect of ramipril on walking times and quality of life among patients with peripheral artery disease and intermittent claudication, a randomized controlled trial. JAMA. 2013;309:453-460.

64. Shahin Y, Mazari F, Chetter I. Do angiotensin-converting enzyme inhibitors improve walking distance in patients with symptomatic lower limb arterial disease? A systematic review and meta-analysis of randomised controlled trials. Int J Surg. 2011;9:209-213.

65. Sobieszczyk P, Eisenhauer A. Management of patients after endovascular interventions for peripheral artery disease. Circulation. 2013;128:749-757.

66. Dake MD, Ansel GM, Jaff MR, et al. Paclitaxel-eluting stents show superiority to balloon angioplasty and bare metal stents in femoropopliteal disease: twelve-month Zilver PTX randomized study results. Circ Cardiovasc Interv. 2011;4:495-504.

67. Strobl FF, Brechtel K, Schmehl J, et al. Twelve-month results of a randomized trial comparing mono with dual antiplatelet therapy in endovascularly treated patients with peripheral artery disease. J Endovasc Ther. 2013;20:699-706.

68. Iida O, Yokoi H, Soga Y, et al. Cilostazol reduces angiographic restenosis after endovascular therapy for femoropopliteal lesions in the Sufficient Treatment of Peripheral Intervention by Cilostazol study. Circulation. 2013;127:2307-2315.

69. Krankenberg H, Schlüter M, Steinkamp HJ, et al. Nitinol stent implantation versus percutaneous transluminal angioplasty in superficial femoral artery lesions up to $10 \mathrm{~cm}$ in length: the femoral artery stenting trial (FAST). Circulation. 2007;116(3):285-292.

70. Dick P, Wallner H, Sabeti S, et al. Balloon angioplasty versus stenting with nitinol stents in intermediate length superficial femoral artery lesions. Catheter Cardiovasc Interv. 2009;74(7):1090-1095.
Therapeutics and Clinical Risk Management

\section{Publish your work in this journal}

Therapeutics and Clinical Risk Management is an international, peerreviewed journal of clinical therapeutics and risk management, focusing on concise rapid reporting of clinical studies in all therapeutic areas, outcomes, safety, and programs for the effective, safe, and sustained use of medicines. This journal is indexed on PubMed Central, CAS,

\section{Dovepress}

EMBase, Scopus and the Elsevier Bibliographic databases. The manuscript management system is completely online and includes a very quick and fair peer-review system, which is all easy to use. Visit http://www.dovepress.com/testimonials.php to read real quotes from published authors. 